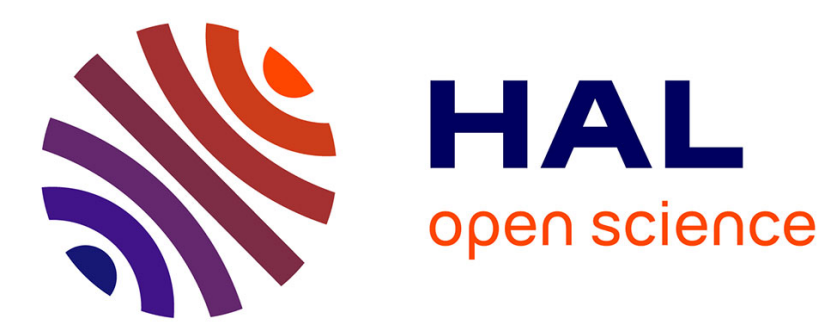

\title{
Capillary rise between closely spaced plates : effect of Van der Waals forces
}

\author{
B. Legait, P.-G. de Gennes
}

\section{To cite this version:}

B. Legait, P.-G. de Gennes. Capillary rise between closely spaced plates : effect of Van der Waals forces. Journal de Physique Lettres, 1984, 45 (13), pp.647-652. 10.1051/jphyslet:019840045013064700 . jpa00232393

\section{HAL Id: jpa-00232393 https://hal.science/jpa-00232393}

Submitted on 1 Jan 1984

HAL is a multi-disciplinary open access archive for the deposit and dissemination of scientific research documents, whether they are published or not. The documents may come from teaching and research institutions in France or abroad, or from public or private research centers.
L'archive ouverte pluridisciplinaire HAL, est destinée au dépôt et à la diffusion de documents scientifiques de niveau recherche, publiés ou non, émanant des établissements d'enseignement et de recherche français ou étrangers, des laboratoires publics ou privés. 


\title{
LE JOURNAL DE PHYSIQUE-LETTRES
}

J. Physique Lett. 45 (1984) L-647 - L-652

1er JUiLlet 1984, PAGe L-647

Classification

Physics Abstracts

$68.10 \mathrm{C}$

\section{Capillary rise between closely spaced plates : effect of Van der Waals forces}

\author{
B. Legait \\ Institut Français du Pétrole, B.P. 311, 92506 Rueil-Malmaison Cedex, France \\ and P. G. de Gennes \\ Collège de France, 75231 Paris Cedex, France
}

(Reçule 20 mars 1984, accepté le 4 mai 1984)

\begin{abstract}
Résumé. - La hauteur capillaire $h$ d'un fluide parfaitement mouillant entre deux plaques parallèles (distantes de $2 R$ ) dépend de l'épaisseur du film à la paroi. Moldover et Gammon [1] ont proposé une réduction de la distance effective entre plaques $2 R_{\text {eff }}$ (à insérer dans la loi de Jurin) telle que $R-R_{\text {eff }}$ soit exactement égal à $Z(h)$ (épaisseur d'un film sur une plaque unique). Nous montrons que le film est en fait épaissi à cause de la présence de la $2^{\mathrm{e}}$ plaque, et que $R-R_{\mathrm{eff}}=1,5 Z(h)$. Ceci améliore la comparaison entre la théorie et les données de Moldover et Gammon sur $\mathrm{SF}_{6}$. L'analyse est limitée à des forces de Van der Waals non retardées.
\end{abstract}

\begin{abstract}
The capillary rise of a perfectly wetting fluid, between two parallel plates ( $2 R$ apart), depends on the thickness of the wetting film. Moldover and Gammon [1] proposed a reduction of the effective spacing between plates $2 R_{\text {eff }}$ (to be included in Jurin's law) such that $R-R_{\text {eff }}$ is exactly equal to $Z(h)$ (the thickness of a film spread on a single plate). We show that the film is thickened due to the second plate, and that $R-R_{\text {eff }}=1.5 Z(h)$. The comparison between theory and the data of Moldover and Gammon on $\mathrm{SF}_{6}$ is thereby improved. The present analysis is restricted to non-retarded Van der Waals forces.
\end{abstract}

During the capillary rise of a perfectly wetting fluid, a thin wetting layer spreads on the solid walls. This process is usually very slow [2]. A wetting layer of sulfur hexafluoride $\left(\mathrm{SF}_{6}\right)$ below and near its critical temperature will reach equilibrium in a few days. M. R. Moldover and R. W. Gammon [1] have measured the thickness $\zeta$ of the wetting film with an interferometric technique, the $\mathrm{SF}_{6}$ imbibing the gap between two parallel plates (the distance $2 R$ between the plates is such that $0.8 \mu \mathrm{m}<2 R<3.5 \mu \mathrm{m})$. For a single vertical plate, the film thickness $\zeta(h)$ may usually be obtained from a balance between gravity forces (which tend to thin the layer) 
and long range Van der Waals forces (which tend to thicken the layer). For relatively thin films (a few hundred angströms) we may take these forces in the non-retarded form [3] :

$$
\rho g h=A / 6 \pi \zeta^{3}
$$

where $h$ is the capillary height, $\rho$ the difference between the densities of $\mathrm{SF}_{6}$ and its vapour, $A$ the Hamaker constant (Figs. 1 and 2).

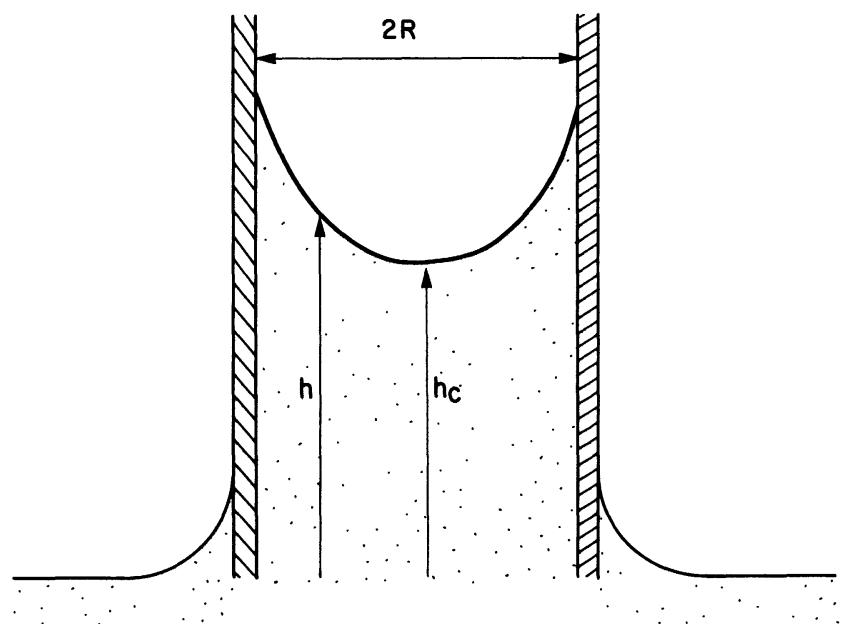

Fig. 1. - Capillary rise between two parallel plates, $2 R$ apart.

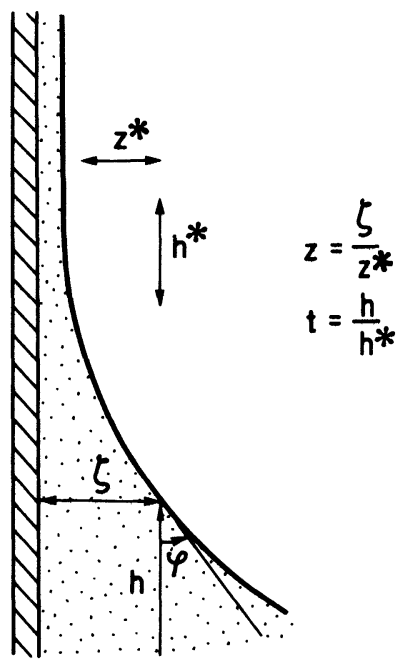

Fig. 2. - Schematic cross section of a wetting film.

Equation (1) has two major limitations :

a) the effects of the interfacial tension $\gamma$ (and of the associated capillary pressures) have been neglected ;

b) equation (1) applies for a single plate : for two parallel plates the coupling between the two films (induced by capillary pressures) leads to a thickening of both films. 
We shall now discuss $(a)$ and $(b)$, incorporating all three forces. The starting point is [4] :

$$
\gamma C=\rho g h-A / 6 \pi \zeta^{3} \Leftrightarrow C=\kappa^{2} h-a^{2} / \zeta^{3} .
$$

where $C$ is the curvature of the interface, $\gamma$ the interfacial tension, and :

$$
\kappa^{2}=\rho g / \gamma \quad a^{2}=A / \sigma \pi \gamma .
$$

Far from the liquid vapour critical point, $a$ is a molecular size. Near the critical point $\left(\tau=\frac{T-T_{\mathrm{c}}}{T_{\mathrm{c}}} \ll 1\right)$ we expect $A \sim \tau^{\beta}, \gamma \sim \tau^{2 v}$, where $\beta$ and $v$ are standard critical exponents [5] : the result is a certain enhancement of the length $a$.

An inner solution of equation (2) (valid if $h \gg h_{\mathrm{c}}+R ; \zeta \ll R, h_{\mathrm{c}}$ being the capillary height of the bottom of the meniscus) and an outer solution (valid if $h \simeq h_{\mathrm{c}}$ and $\zeta \simeq R$ ) will now be calculated and matched.

\section{Outer solution.}

By integrating equation (2) :

$$
\cos \varphi=\kappa^{2} \int_{\zeta}^{R} h(\lambda) \mathrm{d} \lambda-0.5\left[\left(\frac{a}{\zeta}\right)^{2}-\left(\frac{a}{R}\right)^{2}\right]
$$

with $\operatorname{tg} \varphi=-\mathrm{d} \zeta / \mathrm{d} h$. A Taylor expansion gives :

$$
\left.\begin{array}{l}
\int_{\zeta}^{R} h(\lambda) \mathrm{d} \lambda=(R-\zeta) h_{\mathrm{c}}(1+\varepsilon) \\
\varepsilon=\frac{(R-\zeta)^{2}}{6 h_{\mathrm{c}}}\left(\kappa^{2} h_{\mathrm{c}}-\frac{a^{2}}{R^{3}}\right)+\frac{1}{8} \cdot \frac{(R-\zeta)^{3} a^{2}}{h_{\mathrm{c}} R^{4}}+\frac{1}{120} \cdot(R-\zeta)^{4} \kappa^{4}\left(1+\kappa^{2} h_{\mathrm{c}}^{2}\right)+\cdots \\
\lim _{\zeta \rightarrow 0} \varepsilon=0.175\left(\frac{R}{h_{\mathrm{c}}}\right)-0.04 \frac{a^{2}}{R h_{\mathrm{c}}} \ldots
\end{array}\right\}
$$

If Van der Waals forces can be neglected ( $a=0)$, equation (4) reduces to :

$$
\sin \varphi=1-\frac{\kappa^{2}}{2}\left(h^{2}-h_{\mathrm{c}}^{2}\right) \text {. }
$$

The capillary height $h_{\mathrm{c}}$ is obtained by integrating $\mathrm{d} \zeta=-\operatorname{tg} \varphi \mathrm{d} h$ between 0 and $R$; as a first order approximation in $1 / \kappa^{2} h_{\mathrm{c}}^{2}$ :

$$
R h_{\mathrm{c}} \kappa^{2}=1-\frac{1-\pi / 4}{\kappa^{2} h_{\mathrm{c}}^{2}} \simeq 1-0.215 \frac{R}{h_{\mathrm{c}}} .
$$

\section{Inner solution.}

The wetting layer thickness is slowly decreasing with $h$, if $\zeta$ is small compared to $R$. Therefore $\varphi$ is small compared to 1 . Equation (2) then becomes :

$$
\frac{\mathrm{d}^{2} \zeta}{\mathrm{d} h^{2}}=\kappa^{2} h-\frac{a^{2}}{\zeta^{3}} \Leftrightarrow \frac{\mathrm{d}^{2} z}{\mathrm{~d} t^{2}}=t-\frac{1}{z^{3}}
$$


with :

$$
\begin{array}{ll}
\zeta=z . z^{*} & z^{*}=a^{\frac{3}{5}} \kappa^{-\frac{2}{5}} \\
h=t . h^{*} & h^{*}=a^{\frac{1}{5}} \kappa^{-\frac{4}{5}} .
\end{array}
$$

2.1. - A particular solution of (7) is

$$
z_{0}(t)=t^{-\frac{1}{3}}\left(1+\frac{4}{27} t^{-\frac{10}{3}}+\cdots\right)
$$

The leading term corresponds to equation (1). The correction is of order :

$$
t^{-\frac{10}{3}}<\left(\frac{h_{\mathrm{c}}}{z^{*}}\right)^{-\frac{10}{3}} \simeq\left(\frac{a}{R}\right)^{\frac{2}{3}}(R \kappa)^{4} \ll 1 .
$$

$t^{-\frac{10}{3}}$ is smaller than $10^{-8}$ under the experimental conditions of [2] and can be therefore neglected.

2.2. - A more general solution can be derived with the help of a perturbation technique :

$$
z(t)=z_{0}(t)(1+v(t))
$$

where $v$ is assumed to be small $: v \ll 1$.

$$
\begin{gathered}
\text { A solution of the approximated form of }(7): \frac{\mathrm{d}^{2}\left(z_{0} v\right)}{\mathrm{d} t^{2}}=\frac{3 v}{z_{0}^{3}} \text { is } \\
\qquad v(t)=a \mathrm{e}^{-\frac{3 \sqrt{3}}{5} t^{\frac{5}{3}}} .
\end{gathered}
$$

Where $a$ is an arbitrary constant (the terms in $t^{v}$ have been neglected if $v<-5 / 3$ ).

\section{Matching of the inner and outer solutions.}

The capillary height remains approximatively constant between the domains where equation (9) is valid $(v \ll 1)$ and where Van der Waals forces are negligible $\left(v>v_{0}\right.$ with $\left.v_{0}^{3} \gg 1\right)$ :

$$
\frac{h-h_{\mathrm{c}}}{h_{\mathrm{c}}} \simeq \frac{h-h\left(v_{0}\right)}{h_{\mathrm{c}}}<\frac{\left(v_{0}-1\right)}{v} t^{-\frac{5}{3}} .
$$

In the following, it is assumed that a value of $v$ such that :

$$
t^{-\frac{5}{3}} \ll v \ll 1
$$

can be defined (condition (12) can be fulfilled under the experimental conditions of Ref. [2] : $t^{-5 / 3}$ is smaller than $\left.10^{-4}\right)$.

If condition (12) is valid, a good approximation of the first derivative of $z$ is :

$$
\frac{\mathrm{d} z}{\mathrm{~d} t}=-\sqrt{3} t^{\frac{1}{3}} v
$$


Introducing the solution (10) in equation (3) :

$$
\frac{1}{\sqrt{1+3 v^{2}(a \kappa)^{\frac{4}{5}} t^{\frac{2}{3}}}}=\kappa^{2} h_{\mathrm{c}} R(1+\varepsilon)\left[1-\frac{z^{*} t^{-\frac{1}{3}}}{R}(1+v)-0.5\left(\frac{a}{z^{*}}\right)^{2} \cdot \frac{t^{\frac{2}{3}}}{(1+v)^{2}}\right] \text {. }
$$

$h$ being approximated by $h_{\mathrm{c}}$ :

$$
1=\kappa^{2} R h_{\mathrm{c}}(1+\varepsilon)\left[1+1.5 v^{2}\left(\frac{a}{R}\right)^{\frac{2}{3}}\right]\left[1-\left(\frac{a}{R}\right)^{\frac{2}{3}}\left(1+v+\frac{0.5}{(1+v)^{2}}\right)\right] .
$$

Equation (15) reduces to :

$$
1=\kappa^{2} h_{\mathrm{c}} R\left(1+0.175 \frac{R}{h_{\mathrm{c}}}-1.5\left(\frac{a}{R}\right)^{\frac{2}{3}}+\cdots\right) .
$$

(i) The first correction $\left(0.175 \frac{R}{h_{\mathrm{c}}}\right)$ describes a standard correction to Jurin's law of capillary rise : the curvature of the meniscus is not exactly constant, but depends slightly on $h$.

(ii) The second correction describes a reduction of the effective gap between the plates due to the wetting films :

$$
R_{\text {eff }}=R-1.5 a^{\frac{2}{3}} R^{\frac{1}{3}}=R-1.5 Z\left(h_{\mathrm{c}}\right)
$$

where we have made use of equation (1) and of $\kappa^{2} h_{\mathrm{c}} R \simeq 1$ in the correction term.

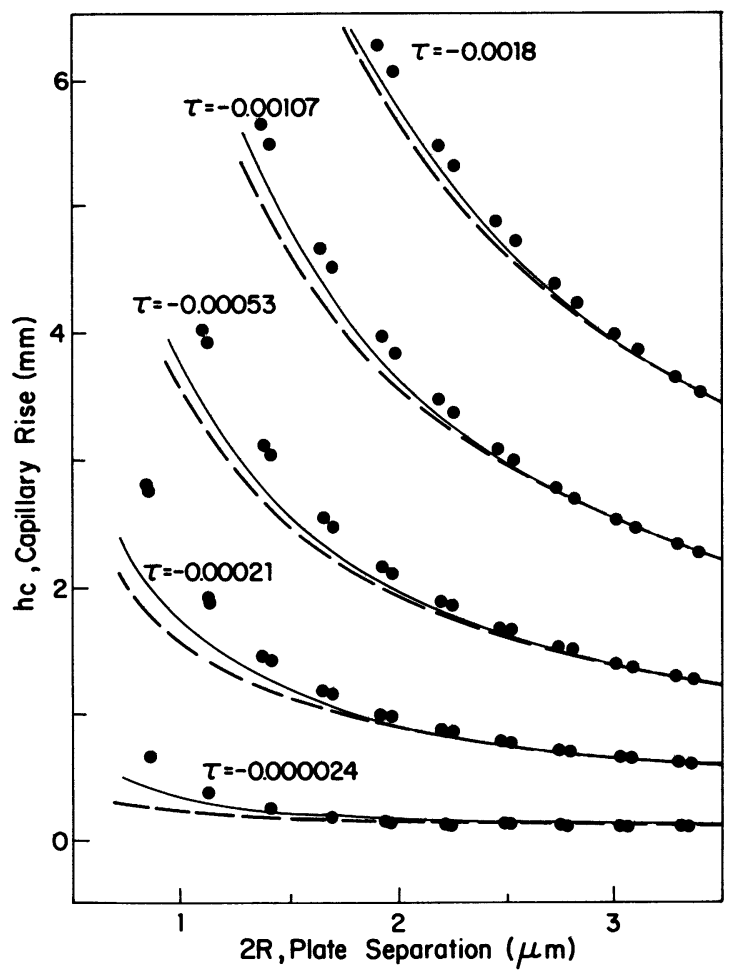

Fig. 3. - Comparison between experimental data of Ref. [1] (๑), Eq. (18) (-) and $\kappa^{2} h c R=1(--)$. 
Equation (17) is our central result. Under the experimental conditions of reference [1] correction (i) is negligible when compared to correction (ii). We see that the general idea of Moldover and Gammon is right : the films reduce the gap. But the coefficient (1.5) is larger than what they anticipated [1].

On figure 3 , the experimental data of reference [1] are compared to :

$$
1=\kappa^{2} h_{\mathrm{c}} R\left(1-1.5\left(\frac{a}{R}\right)^{\frac{2}{3}}\right)
$$

As discussed in [1], the measured film thicknesses $(0.1 \mu \mathrm{m}$ to $0.5 \mu \mathrm{m})$ are in the intermediate region where the transition between the non-retarded and the retarded form of the Van der Waals interaction occurs; retardation tends to thin the films, and thus to increase the discrepancy between equation (18) and the experimental data of reference [1].

\section{Acknowledgments.}

We are indebted to Dr. M. R. Moldover for a preprint of reference [1] and to J. F. Joanny and P. Sourieau for helpful discussions.

\section{References}

[1] Moldover, M. R., Gammon, R. W., J. Chem. Phys. 80 (1984) 528.

[2] De Gennes, P. G., C.R. Hebd. Séan. Acad. Sci., Paris 298 (1984) 111.

[3] Dzialoshinsky, I., Lifshitz, E., PitaevskiI, L., Adv. Phys. 10 (1961) 165.

[4] Churaev, N. V., Starov, V. M., Derjaguin, B. V., J. Colloid Interface Sci. 89 (1982) 16.

[5] Stanley, H., Introduction to phase transitions and critical phenomena (Oxford, Clarendon Press) 1971. 